\title{
Reproductive investment in the crab Cancer setosus along a latitudinal cline: egg production, embryo losses and embryo ventilation
}

\author{
Antonio Brante ${ }^{1}$, Miriam Fernández ${ }^{1, *}$, Lars Eckerle ${ }^{2}$, Felix Mark ${ }^{2}$, \\ Hans-Otto Pörtner ${ }^{2}$, Wolf Arntz ${ }^{2}$ \\ ${ }^{1}$ Estación Costera de Investigaciones Marinas of Las Cruces and Center for Advanced Studies in Ecology and Biodiversity, \\ Departamento de Ecología, Facultad de Ciencias Biológicas, Pontificia Universidad Católica de Chile, Casilla 114-D, \\ Santiago, Chile
}

${ }^{2}$ Alfred-Wegener-Institut, Columbusstrasse, 27568 Bremerhaven, Germany

\begin{abstract}
Reproductive output (RO) is commonly used as a proxy for reproductive effort (RE) among Brachyuran crabs and other marine invertebrates, and so far no attempt has been made to incorporate the cost of brooding into RE to obtain a more reliable estimate of reproductive investment, nor to compare it along a temperature (latitudinal) gradient. We compared RO among 3 sites (ca. 20, 30 and $40^{\circ} \mathrm{S}$, reflecting mean annual sea-surface temperatures of 18,14 and $10^{\circ} \mathrm{C}$, respectively), and the cost of brooding (oxygen provision) at those temperatures, in order to obtain a more reliable pattern of reproductive investment along an extended latitudinal gradient. A total of 187 brooding females of Cancer setosus were collected to estimate RO. Fecundity, volume and weight of the embryos, and embryo losses were also estimated. Laboratory experiments were carried out at the characteristic temperatures of those sites (acclimating females from central Chile) to determine (1) patterns of oxygen provision to the embryos, (2) patterns of brooding behavior, and (3) to quantify the cost of embryo ventilation. Optic fibers, video recording and respiration chambers were used to meet these goals. Results showed that (1) RO, (2) fecundity, and (3) volume and weight of embryos varied with latitude, and that temperature affects (1) period of embryo ventilation (oxygen provision) events, (2) flapping frequency, (3) embryo losses throughout the brooding period, and (4) cost of embryo ventilation per unit of time. While RO increased with latitude, the cost of embryo ventilation decreased with temperature, suggesting a trade-off between investment in eggs and the cost of providing oxygen to the embryos at different temperatures (latitudes). This pattern may not be exclusive to Brachyuran crabs, but may also apply to other marine invertebrates since oxygen limitation during early development occurs in other brooding species.
\end{abstract}

KEY WORDS: Brooding behavior - Latitudinal pattern - Reproductive output $\cdot$ Reproductive effort · Oxygen provision - Embryo development

\section{INTRODUCTION}

Reproductive effort (RE), as a measurement of the energy assigned to reproduction, is a critical factor in the understanding of life history evolution (Stearns 1992). The estimation of RE is very difficult, but in spite of the difficulties, important advances have been made in its estimation among terrestrial organisms (e.g. birds, Masman et al. 1989, Monaghan \& Nager 1997; squirrels, Kenagy et al. 1990). Among marine organisms, especially marine invertebrates, reproductive output (RO) is used as a proxy for RE (Brown \& RussellHunter 1978, Hughes \& Roberts 1980, Hines 1982, Havenhand \& Todd 1989, Grant 1990, Todd 1990, Willows 1990, Coma et al. 1995. However, RO is not always a good estimator of RE (Clarke 1987) especially 
when groups exhibiting contrasting life history patterns are compared. For instance, RO may be a better predictor of RE among broadcasting species than among brooding species of marine invertebrates. Brooding species carry or protect the embryos throughout development, investing substantial amounts of energy in brood care (Menge 1974, Perron 1982, Clarke 1987, Pandian 1994, Fernández et al. 2000).

Among Crustaceans, Brachyuran crabs carry the embryos for extended periods of time (Wear 1974, Hines 1986). During brooding, female crabs exhibit complex behaviors (Hoagland 1979, Hartnoll \& Paul 1982, Naylor et al. 1999, Fernández et al. 2000, Baeza \& Fernández 2002), which seem to be mostly directed towards providing embryos with oxygen (Baeza \& Fernández 2002). Since oxygen consumption of the embryos increases with progressing development, brooding females increase ventilation frequency providing oxygen to the embryos according to their demand (Baeza \& Fernández 2002). This change in brooding behavior is related to a 2 -fold increase in oxygen consumption of brooding females (after discounting oxygen consumption of the embryo mass), when compared to nonbrooding females of similar size (Baeza \& Fernández 2002). This suggests that oxygen provision to the brood may account for a substantial fraction of total reproductive costs. Nonetheless, among Brachyuran crabs RE is traditionally estimated as the ratio between brood weight and female weight, in other words estimating RO (e.g. Hines 1982), which thereby largely underestimates RE.

So far no attempt has been made to incorporate the cost of brooding into RE in order to obtain a more reliable estimate of reproductive investment, and to compare it along temperature (latitudinal) gradients. Several intraspecific comparisons of Brachyuran crabs revealed that RO increases with latitude, as temperature falls (e.g. Lardies \& Castilla 2001). Considering that the oxygen demand of crab embryos increases with increasing temperature (Wheatly 1981), and that females adjust oxygen provision according to embryonic oxygen demand (Baeza \& Fernández 2002), it can be hypothesized that investment in oxygen supply to the brood decreases at lower temperatures (higher latitudes). The present study was undertaken to advance our understanding of latitudinal patterns of reproductive investment among marine invertebrates, focusing on Cancer setosus (Molina 1782), a Brachyuran crab species distributed between 18 and $45^{\circ} \mathrm{S}$ in the Eastern Pacific. RO in C. setosus from 3 sites (ca. 20,30 and $40^{\circ} \mathrm{S}$, reflecting annual mean sea-surface temperatures of 18,14 and $10^{\circ} \mathrm{C}$, respectively) was compared. Taking advantage of this extended latitudinal range, comparisons among sites of (1) fecundity, (2) volume and weight of the embryos, and (3) embryo losses throughout development were also conducted. Laboratory experiments were carried out at the characteristic temperatures of the study area to (1) determine patterns of oxygen provision to the embryos, (2) assess patterns of brooding behavior, and (3) quantify the cost of maternal care. Finally, using these 2 complementary approximations, we show that RO is not a good indicator of investment in reproduction, at least for species exhibiting some sort of embryo protection. This approximation would allow us to obtain a more reliable estimate of reproductive investment (closer to RE) than the traditional approaches used among marine invertebrates, and also to conduct an assessment of the role of temperature and oxygen as constraining factors of brood size. We discuss how the cost of brooding may play a key role in the final balance between investment in eggs and in embryo care in Brachyuran crabs.

\section{MATERIALS AND METHODS}

Cancer setosus (Brachyura, Cancridae) is a shallow water edible crab that supports a commercial fishery along its distributional range. Considering the information available on brooding behavior of this species (see Baeza \& Fernández 2002, Fernández et al. 2003), and its extended latitudinal range of distribution, $C$. setosus was used as a model species to meet the objectives proposed above. Throughout this manuscript we use oxygen provision and oxygen supply as synonymous, and oxygen level (in \% air saturation) as synonymous of oxygen availability. When ANOVA or ANCOVA analyses were carried out, the Cochran and Student-Newman-Keuls (SNK) tests were used to test for homogeneity of variances and to conduct a posteriori comparisons, respectively (Zar 1996).

Fecundity, embryo losses, reproductive output, and embryo volume and weight. In order to estimate fecundity, embryo losses throughout development, RO, embryo volume and embryo weight of Cancer setosus, 187 brooding females were collected in the area surrounding Iquique (northern Chile, $20^{\circ} 14^{\prime} \mathrm{S}, 70^{\circ} 10^{\prime} \mathrm{W}$ ), between Coquimbo and San Antonio (central Chile; $29^{\circ} 58^{\prime} \mathrm{S}, 71^{\circ} 22^{\prime} \mathrm{W}$ and $33^{\circ} 36^{\prime} \mathrm{S}, 71^{\circ} 38^{\prime} \mathrm{W}$, respectively) and around Puerto Montt (southern Chile, $41^{\circ} 32^{\prime} \mathrm{S}$, $72^{\circ} 59^{\prime} \mathrm{W}$; Fig. 1), hereafter referred to as north, center and south, respectively. Samples were collected by local fishermen at depths ranging between 0 and $15 \mathrm{~m}$, between February 1999 and December 2000 (several visits to each sampling site) and were frozen immediately for later analysis. Carapace width (CW) of brooding females was measured and females were categorized according to the developmental stage of their embryos. Two developmental stage categories were 
used (Vargas 1995): (1) early (from embryos exhibiting uniformly distributed yolk, absence of cleavage and eyes, to embryos with cleavage and yolk reduced to not less than $75 \%$ of embryo volume; Fernández et al. 2002) and (2) late (from embryos displaying pigments and visible but undeveloped eyes, to embryos with welldeveloped eyes, a pumping heart, and appendages). According to this categorization, the sample size for females carrying early-stage embryos was 35 in the north, 24 in the center and 33 in the south, and for females carrying late-stage embryos was 38 in the north, 39 in the center and 18 in the south. This sample size was used to estimate fecundity, embryo losses and RO.

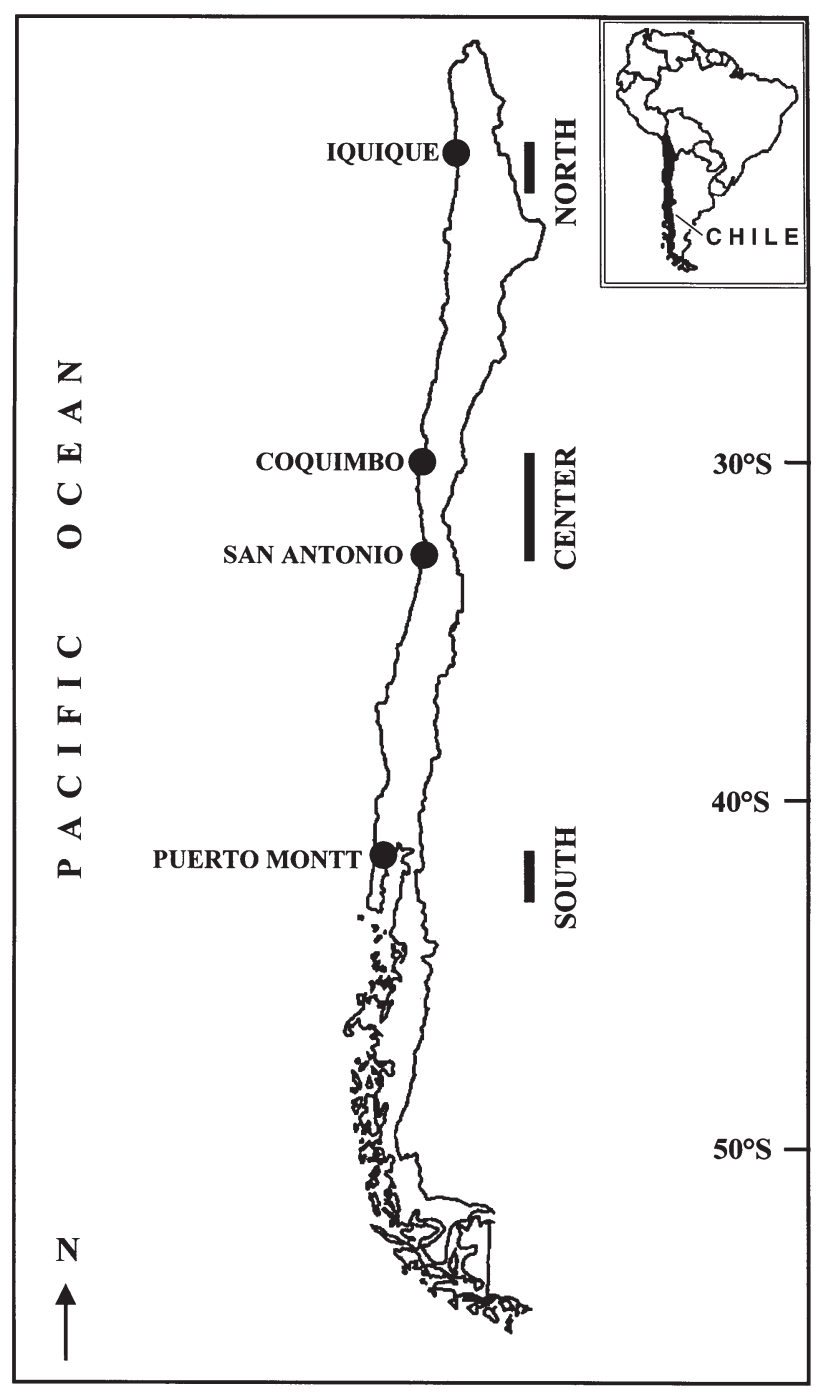

Fig. 1. Map of Chile showing sampling sites. In northern Chile, several sites around Iquique $\left(20^{\circ} 14^{\prime} \mathrm{S}, 70^{\circ} 10^{\prime} \mathrm{W}\right)$ were sampled. In central Chile, crabs were collected at several sites located between Coquimbo and San Antonio $\left(29^{\circ} 58^{\prime} \mathrm{S}\right.$, $71^{\circ} 22^{\prime} \mathrm{W}$ and $33^{\circ} 36^{\prime} \mathrm{S}, 71^{\circ} 38^{\prime} \mathrm{W}$, respectively). In southern Chile, samples were collected in the area of Puerto Montt $\left(41^{\circ} 32^{\prime} \mathrm{S}, 72^{\circ} 59^{\prime} \mathrm{W}\right)$
In order to estimate fecundity, 3 subsamples (up to $0.005 \mathrm{~g}$ ), randomly taken from the border of each embryo mass, were weighed and the number of embryos in those samples were counted. Fecundity was estimated by extrapolating the ratio between number of embryos and dry weight of the sample to the total embryo mass dry weight. In this case, females incubating early- and late-stage embryos were used (see below) to estimate not only fecundity, but also to obtain an indirect estimate of embryo losses, by comparing fecundity of females carrying early- and late-stage embryos. It was assumed that estimates of embryo losses between the 2 stages, using different female individuals for each stage, would yield similar results as when following embryo losses of the same female throughout development. This approach allowed us to explore latitudinal trends in embryo losses (due to unidentified causes, such as natural mortality or mechanical action). Fecundity was compared among sites and between developmental stages with a 2-factor ANCOVA (mixed model) using $\mathrm{CW}$ as the covariate. Data were log-transformed.

In order to exclude erroneous underestimation or overestimation of RO owing to embryo losses (Kuris 1991) or embryo growth, respectively, only females carrying early-stage embryos were used. Wet weight (g) of females and embryo masses were obtained separately (see below), and then all samples were ovendried for $24 \mathrm{~h}$ at $100^{\circ} \mathrm{C}$. Body dry weight (BDW, g) of brooding females (excluding the brood mass) and dry weight of embryo masses were recorded and used to estimate RO. BDW of brooding females (excluding the embryos) ranged between 26.4 and $220 \mathrm{~g}$ (mean $\pm \mathrm{SD}$ : north $=83.7 \pm 28.4 \mathrm{~g}$; center $=89.3 \pm 42.7 \mathrm{~g}$; and south $=85.7 \pm 46.1 \mathrm{~g}$ ). Given that brood size is strongly correlated with body size, and to avoid any erroneous interpretation of RO pattern due to differences in body size range among sites, a Kolmogorov-Smirnov test was conducted to test for differences in BDW frequency distribution among sites. Since no differences in BDW were found among sampling sites (always p > 0.1 ), mean RO was compared among sites using a 1-way ANOVA.

In order to estimate mean embryo volume $\left(\mathrm{mm}^{3}\right), 10$ embryos were randomly removed from the border of each early stage embryo mass and measured in their longest and shortest diameters. For numbers of replicates for each sampling site, see Fig. 3. The mean of both diameter measurements was used to estimate the volume of the embryos (volume of a sphere). Finally, mean volume of the 10 embryos was estimated for each female, and these values were used for statistical comparisons. Mean dry weight ( $g$ ) of early-stage embryos was calculated from the relationship between subsample dry weight and embryo number used to estimate 
fecundity (see above). ANOVA were conducted to test for differences in (1) embryo volume and (2) embryo dry weight among sites. Embryo volume data were square-root transformed in order to meet the assumptions of ANOVA.

Patterns of oxygen provision to the embryo mass, brooding behavior and metabolic cost of brooding at different temperatures. Females of Cancer setosus were collected in central Chile by local fishermen between 0 and $15 \mathrm{~m}$ depth. Crabs were fed ad libitum on fresh mussels Choromytilus chorus while maintained in holding tanks. All experiments were conducted within 2 wk of collection. Females were maintained for $48 \mathrm{~h}$ before experiments started at temperatures characteristic of the study sites (south, $10^{\circ} \mathrm{C}$; center, $14^{\circ} \mathrm{C}_{i}$ and north $18^{\circ} \mathrm{C}$ ). These are mean annual sea-surface temperatures calculated using information from the last $10 \mathrm{yr}$ (Servicio Hidrográfico y Oceanográfico de la Armada de Chile 1996). However, temperature does not vary on average more than 1 or $1.5^{\circ} \mathrm{C}$ between surface water and 10 to $15 \mathrm{~m}$ depth (Diego Narváez pers. comm.). A series of experiments were conducted to determine the link between oxygen demand of crab embryos, brooding behavior and oxygen provision to the embryos, and to establish the cost associated with oxygen provision.

Patterns of oxygen provision to the embryo mass: Laboratory experiments were conducted to determine whether patterns of oxygen provision to the embryos varied with temperature (Baeza \& Fernández 2002), following oxygen demand of the embryos (Wheatly 1981). The experimental protocols described by Baeza \& Fernández (2002) were applied. Experimental factors were temperature ( 3 levels: 10,14 and $18^{\circ} \mathrm{C}$ ) and embryo stage (2 levels: females carrying early- and late-stage embryos). After acclimation, brooding females were placed individually in 161 transparent plastic tanks $(25 \times 25 \times 25 \mathrm{~cm})$ filled with a $2 \mathrm{~cm}$ layer of shell hash, a large rock, and aerated sea water maintained at a constant experimental temperature.

Oxygen availability in the center of embryo masses was monitored continuously with a Presens microoptode, using an optic fiber (tip diameter approximately $100 \mu \mathrm{m})$. The fiber was placed in the center of embryo masses by drilling a small hole through the 6th abdominal segment of each brooding female (see Baeza \& Fernández 2002 for more details). Previous studies conducted with Cancer setosus (Baeza \& Fernández 2002) and other crab species (Ruiz-Tagle et al. 2002) excluded any artefactual effects of the optic fiber on patterns of oxygen provision, female behavior and female mortality. Embryos were not affected by the procedure. The microoptode was calibrated to 0 and $100 \%$ air saturation (solution saturated with $\mathrm{Na}_{2} \mathrm{SO}_{3}$ and aerated water, respectively) and glued to the abdomen. Oxygen level was recorded (every 5 s) only during the night ( $12 \mathrm{~h}$; see Ruiz-Tagle et al. 2002). For numbers of replicates for each combination of temperature and developmental stage, see Fig. 4. The data recorded were used to (1) show general patterns of oxygen provision to the embryos at different temperatures and for different developmental stages, (2) compare the patterns of oxygen provision among temperatures and stages, using the mean amplitude of oxygen provision cycles, and (3) analyze the effects of different oxygen provision patterns on the average proportion of time that embryos were exposed to low oxygen levels at different temperatures and stages (see Fernández et al. 2000, Baeza \& Fernández 2002). A time series analysis was conducted to detect cycles in oxygen availability. Spectral analyses of oxygen recordings were conducted to determine the dominant frequency in each time series. In each replicate the 5 largest periodogram peaks (frequency domains) were recorded, transformed to period, and expressed in minutes needed to complete 1 full cycle. A 1-way ANOVA was used to test for differences in the mean amplitude (min) of the ventilation cycles among temperatures. Given that no cycle in the pattern in oxygen availability for late-stage embryo masses was evident (see 'Results'), only early-stage masses exposed to different temperature treatments were compared. Data were natural-log transformed in order to meet the assumptions of ANOVA.

The effect that the patterns of oxygen provision by brooding females had on the proportion of time that early- or late-stage embryos were exposed to low oxygen levels $(<25 \%$ air saturation) was estimated. This category was used because oxygen levels of $<25 \%$ air saturation cause a reduction of the embryo's oxygen consumption (Naylor et al. 1999, Fernández et al. 2000, Baeza \& Fernández 2002). A 2-way ANOVA (fixed factors) was used to compare the mean proportion of time of exposure of the embryos to low oxygen levels between stages and among temperatures. Data were arcsine-square root transformed to meet the assumptions of ANOVA.

Brooding behavior: While oxygen availability in the embryo mass was being monitored, female behavior was videotaped using a Sony (time-lapse) video recorder and a Pelco vigilance camera (using infrared light). A $1 \mathrm{~h}$ block was randomly selected and analyzed for each experimental female (when females were facing frontally or diagonally to the camera), from the $12 \mathrm{~h}$ recording period. Within each $1 \mathrm{~h}$ block, the total time that females flapped their abdomen was recorded. Nonbrooding females were not videotaped because they do not perform abdominal flapping as part of their normal behavior (Baeza \& Fernández 2002). A 2-way ANOVA (fixed factors) was used to compare the mean 
number of flapping events per hour among temperatures and between embryo stages. Data were naturallog transformed in order to meet the assumptions of ANOVA.

Metabolic cost of brooding at different temperatures: In order to estimate the metabolic cost of brooding at different temperatures, 3 sets of data were needed: (1) oxygen consumption of nonbrooding females and total oxygen consumption of each brooding female plus its embryo mass, (2) oxygen consumption of the embryos at the same experimental temperatures, and (3) the relationships between CW and female wet weight and between CW and embryo mass wet weight. Data sets 2 and 3 were used to estimate the oxygen consumption of the embryo mass, which was to be subtracted from the total oxygen consumption of each brooding female plus its embryo mass in order to obtain an estimate of the oxygen consumption of the female. Differences in oxygen consumption between brooding and nonbrooding females were assumed to be due to the cost of brooding. Two factors were considered in this experimental design: (1) female condition (nonbrooding, and brooding females carrying early- or late-stage embryos), and (2) temperature (10, 14 and $18^{\circ} \mathrm{C}$ ). For numbers of replicates for each combination of treatments, see Fig. 5. CW of brooding females was measured, and females were then introduced individually into a respiration chamber (11 l) maintained at the experimental temperature (see Baeza \& Fernández 2002 for more details). The electrodes were calibrated in between replicates to 0 and $100 \%$ air saturation (solution saturated with $\mathrm{Na}_{2} \mathrm{SO}_{3}$ and aerated water, respectively) and oxygen depletion (not below $80 \%$ air saturation) was then monitored continuously. Then, oxygen consumption per gram of female wet weight was estimated (see below).

In order to estimate oxygen consumption of earlyand late-stage embryos at the 3 experimental treatments, a double-wall closed microchamber, filled with $2 \mathrm{ml}$ of stirred, filtered $(0.2 \mu \mathrm{m})$ seawater, was used. Electrodes and calibration procedures were applied as described above. A small number of embryos were removed from the border of the embryo mass of females maintained at each experimental temperature, and placed on a fine grid in the microchamber. Oxygen depletion (to a minimum of $80 \%$ air saturation) was monitored continuously for variable time periods, depending on embryo stage and temperature. For numbers of replicates for each combination of treatments, see Fig. 5; embryos from different females were used in each replicate. Oxygen consumption per unit of embryo wet weight was estimated for each replicate $\left(\mu \mathrm{mol} \mathrm{g}{ }^{-1} \mathrm{~min}^{-1}\right)$. A 2-way ANOVA was used to test for differences in oxygen consumption of crab embryos depending on temperatures and embryo stage.
For an estimate of oxygen consumption of brooding females, the value of oxygen consumption of the whole brood was needed. Since we intended to minimize the scale of sacrifice of specimens, the expected weight of the brood mass was calculated for any given female size and embryo stage using the following relationships between female $\mathrm{CW}$ and embryo mass wet weight: (1) early-stage embryos: log embryo wet weight $=2.58(\log$ female CW $)-3.60\left(R^{2}=0.75\right.$, $\mathrm{p}<0.05)$ and (2) late stage: $\log$ embryo wet weight $=$ 2.35 (log female CW) - $2.99\left(\mathrm{R}^{2}=0.84, \mathrm{p}<0.05\right)$. Female wet weight was estimated indirectly from the equation: $\log$ female wet weight $=2.88$ (log female CW $)-3.54\left(R^{2}=0.93, p<0.05\right)$. The high coefficients of determination of the regression analyses indicate that the error involved is small. After embryo mass wet weight was estimated, oxygen consumption of the embryo mass was obtained as the product of the expected wet weight of the embryo mass and the rate of oxygen consumption of embryos per gram of wet weight, for the same developmental stage. Thus, oxygen consumption of brooding females was obtained by subtracting oxygen consumption of the brood $\left(\mu \mathrm{mol} \mathrm{g}{ }^{-1} \mathrm{~min}^{-1}\right.$ ). Then, oxygen consumption of female crabs was compared among temperatures and female conditions using a 2-way ANOVA.

\section{RESULTS}

\section{Fecundity, embryo losses, reproductive output, and embryo volume and weight}

Fecundity and embryo losses

Fecundity fluctuated between 208798 and 2564920 embryos. Log fecundity was positively correlated with $\log$ CW for all developmental stages and sites (always $\mathrm{p}<0.05$; Fig. 2). A positive allometric relationship between both variables was found for all sites and developmental stages. This means that smaller female crabs carried fewer embryos per unit of body size than larger crabs. A significant interaction in ANCOVA precluded us from testing for the effect of sampling site and developmental stage on fecundity (ANCOVA; $\left.F_{2,181}=6.21, \mathrm{p}<0.01\right)$. The interaction term was significant because the difference in fecundity (after statistically controlling for variation in CW) between females carrying early- and late-stage embryos did not follow a constant pattern among sites (latitudes). Fecundity was higher in females carrying early- than those carrying late-stage embryos in northern Chile $(p<0.05)$ but no differences were found within the other 2 study sites ( $>0.05$; Fig. 2). Fecundity of females carrying earlystage embryos was lower in central than in southern 

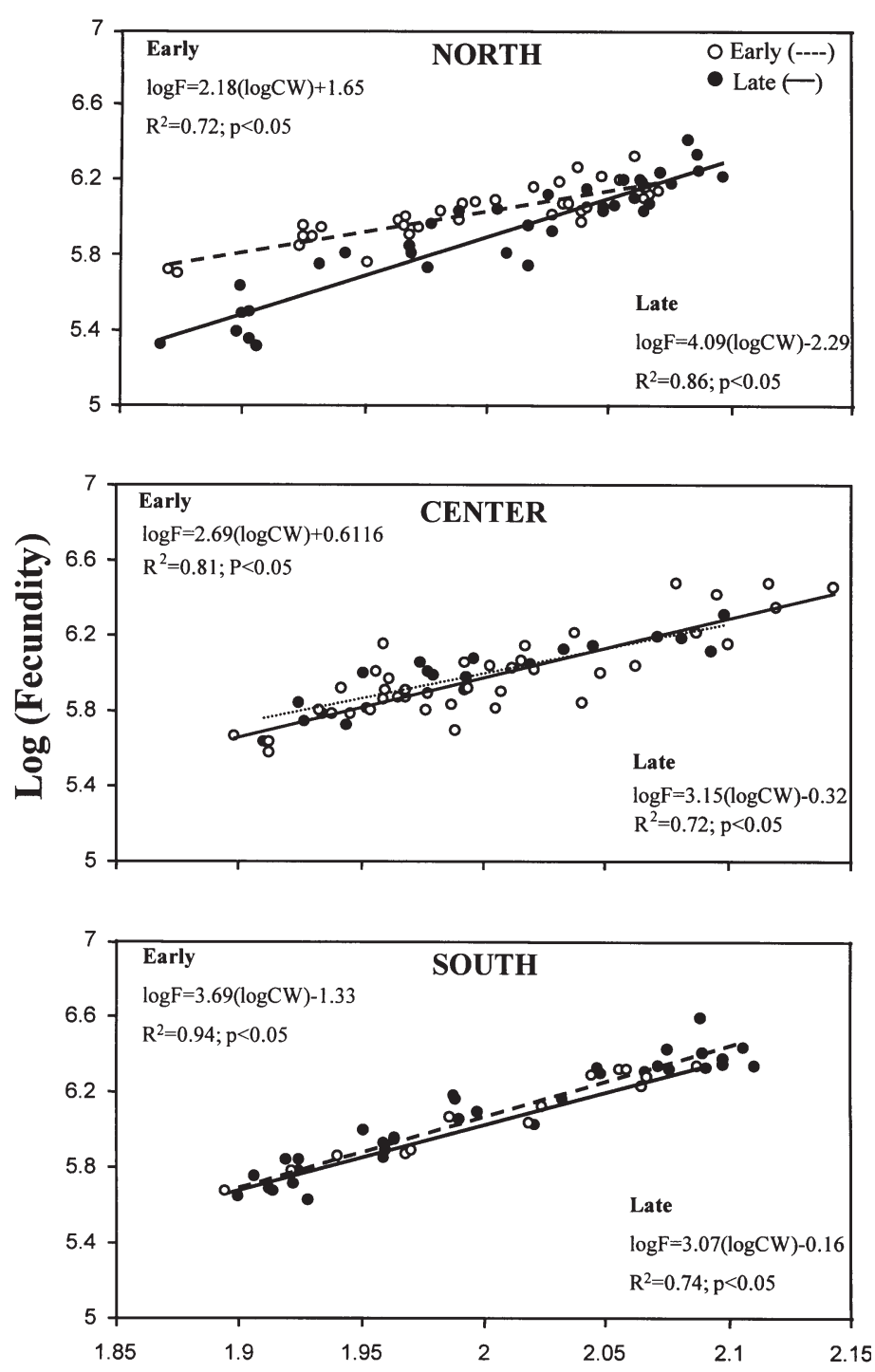

\section{Log (Carapace width)}

Fig. 2. Cancer setosus. Log of fecundity (F) versus log of carapace width (CW) for female crabs from the 3 study sites (north, center and south) along the coast of Chile. White and black circles represent fecundity of crabs carrying early- and late-stage embryos, respectively. Regression equations and determination coefficients $\left(\mathrm{R}^{2}\right)$ are also shown. The same scale was used in the 3 graphs

Chile $(\mathrm{p}<0.05)$; no significant differences were detected between northern and central Chile, nor between north and south $(\mathrm{p}>0.05)$.

\section{Reproductive output}

Significant differences in RO of females carrying early-stage embryos among sampling sites were de- tected $\left(\mathrm{ANOVA}_{i} F_{2,89}=17.23, \mathrm{p}<0.0001 ;\right.$ Fig. $\left.3 \mathrm{~A}\right)$. The SNK a posteriori test showed that RO was significantly lower in the north than the other 2 sites. No significant difference in $\mathrm{RO}$ was detected between the center and the south.

\section{Volume and weight of embryos}

The mean volume of early stage embryos varied between 0.023 and $0.028 \mathrm{~mm}^{3}$ and was significantly different among sampling sites (ANOVA; $F_{2,56}=6.67$, $\mathrm{p}<0.01$; Fig. 3B). A posteriori comparisons showed that embryo volume was significantly smaller in the north than at the other sampling sites (p always $<0.05$ ). A similar pattern was found for embryo dry weight, which increased significantly between northern and
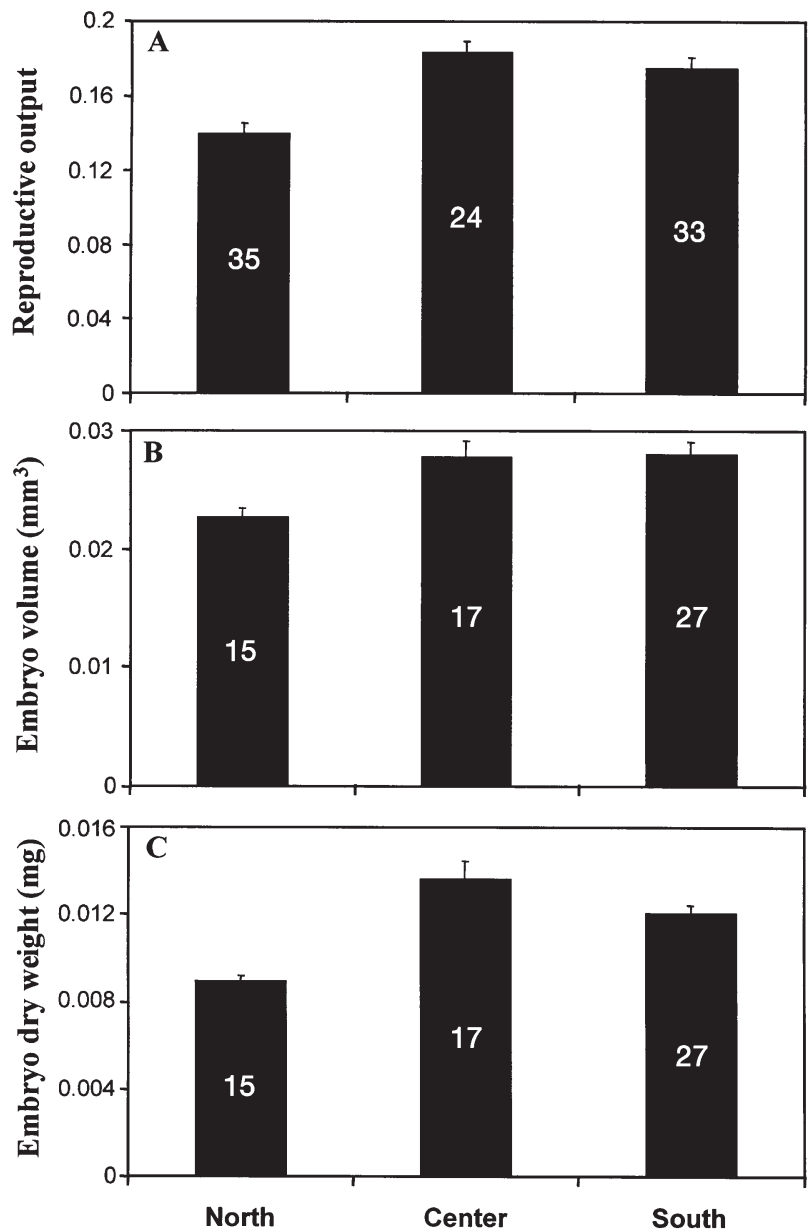

Fig. 3. Cancer setosus. Latitudinal comparisons of reproductive variables of brooding females carrying early-stage embryos for the 3 study sites (north, center and south).

(A) Reproductive output; (B) mean embryo volume $\left(\mathrm{mm}^{3}\right)$; and (C) mean embryo dry weight (mg). Number of replicates are shown inside each bar. Vertical lines indicate +1 SE 
central Chile $\left(\right.$ ANOVA; $F_{2,89}=22.3, \mathrm{p}<0.001$. SNK a posteriori test; $\mathrm{p}<0.01$; Fig. $3 \mathrm{C}$ ). No differences were detected between central and southern Chile (SNK a posteriori test, $\mathrm{p}>0.05$ ).

\section{Patterns of oxygen provision to the embryo mass, brooding behavior and metabolic cost of brooding at different temperatures}

Patterns of oxygen provision to the embryo mass

Clear differences were observed in the pattern of oxygen provision to the embryos incubated in the center of the brood mass between developmental stages and among temperatures. Inserts in Fig. 4A show the general pattern of oxygen availability in the embryo mass for each treatment (temperature and stage). Although each graph represents only 1 female, these patterns were consistently observed in all females and all treatments. Visual inspection of these patterns evidenced clear differences between developmental stages and temperatures. While early-stage embryos were exposed to alternating normoxic or hypoxic periods, with a clear cyclic pattern in oxygen provision, late-stage embryos spent most of the time at high oxygen levels ( $>50 \%$ air saturation). For early-stage embryo masses, the shape of the oxygen-level pattern suggests that oxygen depletion rates within each cycle increased at higher temperatures. Spectral analysis showed that the mean period (time to complete a full cycle) differed significantly among temperatures (ANOVA; $F_{2,11}=8.29, \mathrm{p}<0.01$; Fig. 4A). Crabs (embryo masses) acclimated at $18^{\circ} \mathrm{C}$ displayed a significant decrease in the mean period of oxygen availability compared to those at the other 2 experimental temperatures (SNK a posteriori test, $\mathrm{p}<0.01$ ). No cycles of oxygen availability were observed among females carrying late-stage embryos.

The mean proportion of time that embryos spent at low oxygen levels $(<25 \%$ air saturation) was significantly different between embryo stages (ANOVA; $F_{1,22}=37.38, \mathrm{p}<0.001$; Fig. $\left.4 \mathrm{~B}\right)$, but no effect of temperature was found (ANOVA; $F_{1,22}=1.74, \mathrm{p}<0.001$; Fig. 4B). Early-stage embryos spent most of the time at low oxygen levels while late-stage embryos were rarely exposed to low oxygen levels. Interaction terms were not significant (ANOVA: $F_{2,22}=1.29, \mathrm{p}>0.05$ ).

\section{Brooding behavior}

The frequency of abdominal flapping varied significantly with temperature (ANOVA; $F_{2,20}=27.53$, $\mathrm{p}<0.001)$ and developmental stage $\left(\right.$ ANOVA $_{i} F_{1,20}=$
471.51, $\mathrm{p}<0.001$; Fig. 4C). The interaction term was not significant (ANOVA; $F_{2,20}=0.47, \mathrm{p}>0.1$ ). Female crabs carrying embryos acclimated to $14^{\circ} \mathrm{C}$ showed a $40 \%$ increase in the frequency of abdominal flapping in comparison to females acclimated to $10^{\circ} \mathrm{C}$. In turn, females acclimated to $18^{\circ} \mathrm{C}$ doubled flapping frequency with respect to females acclimated to $10^{\circ} \mathrm{C}$. A dramatic increase in abdominal flapping by an average factor of 8 was found between females carrying early- and latestage embryos. In females carrying late-stage embryos,

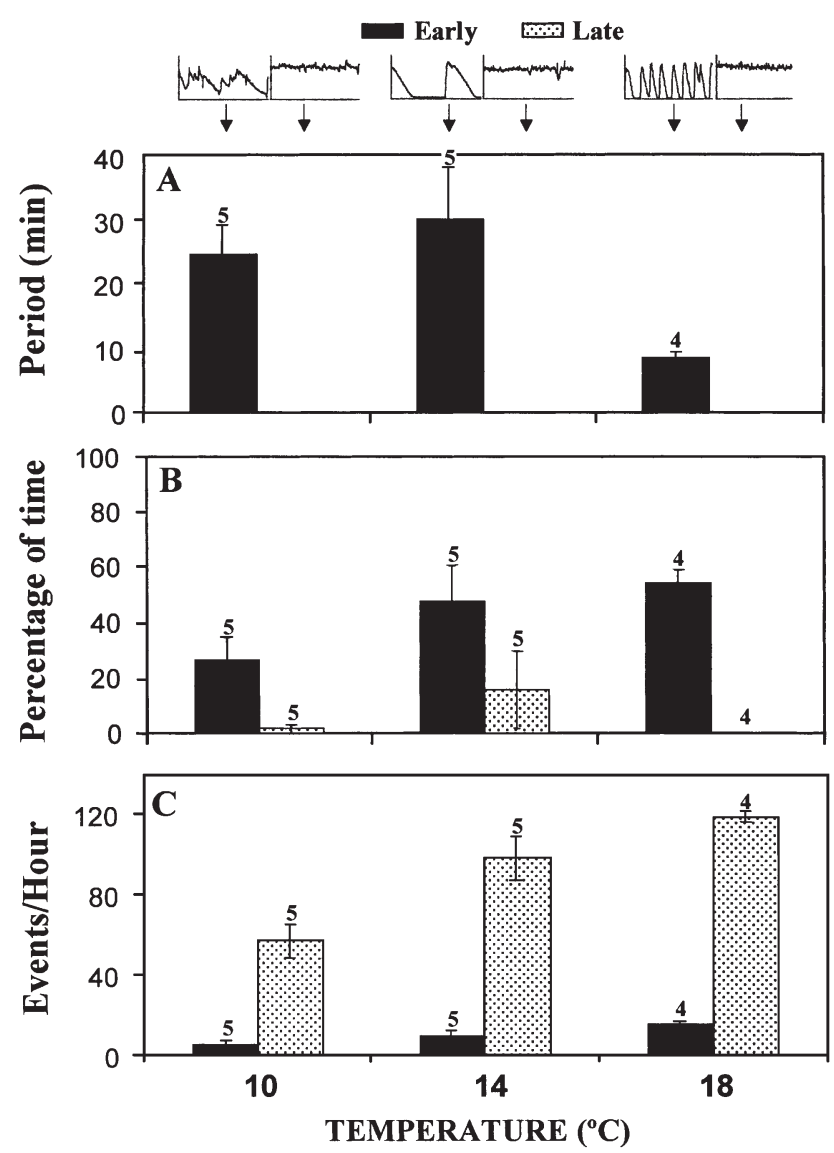

Fig. 4. Cancer setosus. Female crab behavior and patterns of oxygen provision to the embryo mass. Females were collected in central Chile and acclimated at 10,14 and $18^{\circ} \mathrm{C}$. (A) Average length of the main period (min) of the oxygen availability cycle measured at the center of the brood mass of females carrying early-stage embryos is shown. Inserts in the main graph show the patterns of oxygen availability in the embryo mass at different temperatures and developmental stages over a period of $1 \mathrm{~h}$. Each insert represents one female crab (see 'Results'); (B) mean percentage of time that embryos in the center of the mass spent at low oxygen levels $(<25 \%$ air saturation). Oxygen availability was always $<25 \%$ air saturation in embryo masses of late-stage embryos at $18^{\circ} \mathrm{C}_{i}$ (C) frequency of abdominal flapping (events $\mathrm{h}^{-1}$ ) of female crabs carrying embryos at early and late stages. Number of replicates are shown at the top of each bar. Vertical lines indicate $\pm 1 \mathrm{SE}$ 
the increment in flapping frequency between 14 and $18^{\circ} \mathrm{C}$ was lower than between 10 and $14^{\circ} \mathrm{C}$, indicating an asymptotic approach to a maximum rate.

\section{Metabolic costs of brooding}

Oxygen consumption of female crabs increased with temperature $\left(\mathrm{ANOVA}_{i} F_{2,59}=128.9 ; \mathrm{p}<0.0001\right)$ and embryo stage $\left(\right.$ ANOVA $_{i} F_{2,59}=58.7, \mathrm{p}<0.0001$; Fig. 5A). The interaction term was not significant $\left(\right.$ ANOVA $; F_{4,59}=0.95, \mathrm{p}>0.1$ ). Oxygen consumption of female crabs was highest at $18^{\circ} \mathrm{C}$, intermediate at $14^{\circ} \mathrm{C}$, and lowest at $10^{\circ} \mathrm{C}$. A 3 -fold increase in oxygen consumption was recorded in females acclimated to $18^{\circ} \mathrm{C}$, in comparison with those maintained at $10^{\circ} \mathrm{C}$. Oxygen consumption of female crabs carrying latestage embryos was 2 times higher than oxygen consumption of any of the other 2 female conditions ( $p<0.05$; Fig. 5A). No difference in oxygen consumption was detected between nonbrooding and brooding females carrying early-stage embryos ( $p>0.05)$. Changes in oxygen consumption with temperature were non-exponential.

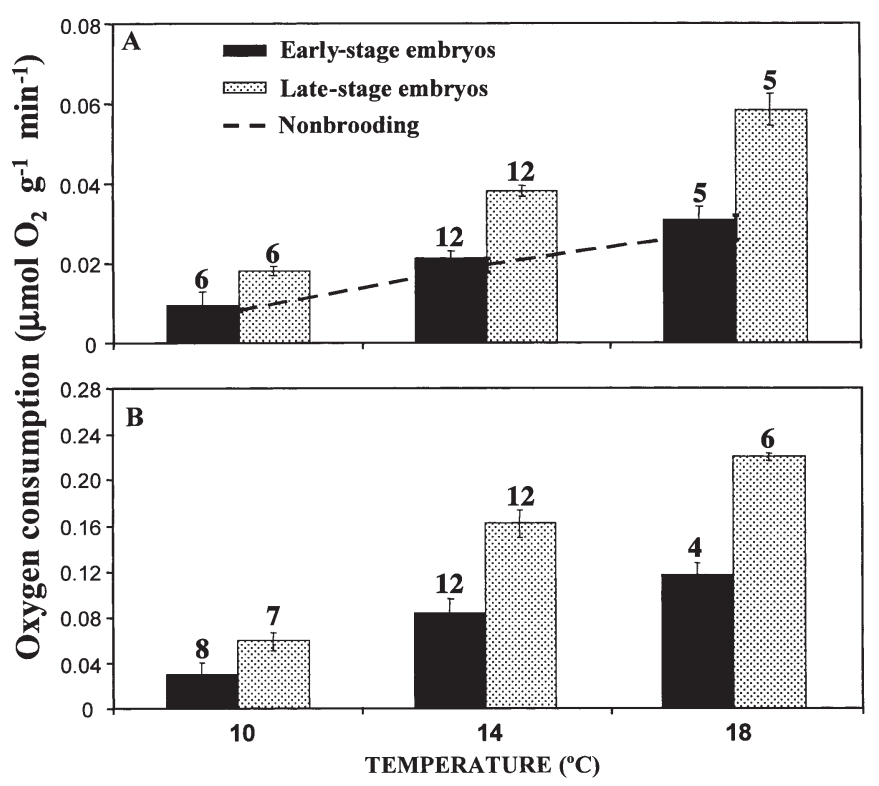

Fig. 5. Cancer setosus. Oxygen consumption $\left(\mu \mathrm{mol} \mathrm{O}_{2} \mathrm{~g}^{-1}\right.$ $\mathrm{min}^{-1}$ ) of female crabs and embryos collected in central Chile and acclimated at temperatures characteristic of northern, central and southern Chile $\left(18,14\right.$, and $10^{\circ} \mathrm{C}$, respectively). (A) Oxygen consumption of nonbrooding (no eggs) and brooding females (calculated by subtracting the oxygen consumption of the brood mass). Numbers of replicates for nonbrooding females were 11, 6 and 5 for experiments conducted at 10,14 and $18^{\circ} \mathrm{C}$, respectively; (B) oxygen consumption of early- and late-stage embryos. Vertical lines indicate $\pm 1 \mathrm{SE}$.

Number of replicates are shown at the top of each bar
A similar pattern was observed for oxygen consumption of crab embryos (Fig. 5B). Oxygen consumption increased significantly as embryos developed (ANOVA; $\left.F_{1,43}=41.2, \mathrm{p}<0.001\right)$ and as temperature increased $\left(\right.$ ANOVA $; F_{1,43}=47.5, \mathrm{p}<0.001$; SNK test, $10<14<$ $18^{\circ} \mathrm{C}$ ). The pattern of increase in oxygen consumption of crab embryos between embryo stages and among temperatures resembled those reported for brooding females. Late-stage embryos doubled the metabolic rate of early-stage embryos. More than a 3-fold increase in oxygen consumption of crab embryos was found between 10 and $18^{\circ} \mathrm{C}$. Changes in oxygen consumption were, again, non-exponential and the increase in oxygen demand between 14 and $18^{\circ} \mathrm{C}$ was smaller than between 10 and $14^{\circ} \mathrm{C}$.

\section{DISCUSSION}

We report the first evidence of the effect of temperature on reproductive investment of the Brachyuran crab Cancer setosus, taking into account not only the partial investment in eggs but also the cost of supplying oxygen to the embryos. We combined field data and laboratory experiments, using females acclimated at 3 different temperatures, and obtained consistent results showing that (1) RO, (2) fecundity, (3) volume and weight of embryos, and (4) embryo losses throughout the brooding period vary with latitude, while temperature affects (1) the period of embryo ventilation (oxygen provision) events, (2) flapping frequency, and (3) cost of brooding per unit of time (Fig. 6). The consistent patterns shown by both sets of data give support to our experimental approach (Fig. 6, Table 1), using females from central Chile acclimated to the 3 experimental temperature characteristics of our study sites.

A lineal allometric relationship between log CW and log fecundity was observed in all sites and both developmental stages, a pattern also reported for other Brachyuran crabs (Hines 1982). According to Hines (1982), allometric limitation on space available for yolk accumulation in the body cavity would be the main constraint on brood size. However, the expected tradeoff between embryo size and number of embryos per brood was not found (Hines 1982). Instead, both higher fecundity and larger embryo sizes were found in females from southern Chile. As of yet, there is no strong evidence supporting latitudinal trends in causal factors as to explain latitudinal clines in embryo size. Smaller and lighter embryos at the lower latitudes may reflect consequences of thermal adaptation to higher mean temperatures. This interpretation is in line with a general trend observed among marine invertebrates in that, at the same activity levels, colder water tempera- 
tures, owing to higher levels of dissolved oxygen, allow for larger body sizes than found in warm water species of the same systematic group (Chapelle \& Peck 1999 for amphipods; Pörtner 2002 for cephalopods). This trend may extend to embryo size, which would also benefit from elevated oxygen solubility. Larger amounts of yolk deposited in embryos incubated in colder waters may result in longer incubation times (Wear 1974), although differences in oxygen consumption among temperatures might also affect developmental rate. Longer developmental times have been reported for low temperatures; for the temperature range of this study, an average decrease of the incubation time of $76 \%$ between 10 and $14^{\circ} \mathrm{C}$ and of $60 \%$ between 14 and $18^{\circ} \mathrm{C}$ can be expected, based on reports from other crab species (our Table 1, based on Wear 1974). Larger, yolky eggs which produce larger larvae are considered to be better able to survive variable conditions such as predation, starvation, salinity and desiccation (Steele \& Steele 1975, Schuh \& Diesel 1995, Diesel \& Schuh 1998). This may be particularly critical during the extended developmental period expected at low temperatures. Acquiring larger sizes at settlement may also have several advantages,

Table 1. Cancer setosus. Summary of the changes (\%) in reproductive output between 2 continuous sampling sites, and in flapping frequency and cost of brooding per minute between temperatures characteristic of those sites for females carrying early- and late-stage embryos. Reproductive output was measured only for early-stage embryos. The differences in incubation time (\%), as an average of those reported for several Crustacean species between experimental temperatures, are shown. Cost of brooding per incubation period was calculated by extrapolating the cost of brooding per minute to the total time of incubation at each temperature. Positive values indicate that as temperature increases

(latitude decreases), the response of the dependent variable also increases

\begin{tabular}{|c|c|c|c|c|}
\hline \multirow[t]{2}{*}{ Response variables } & \multicolumn{2}{|c|}{$\begin{array}{c}\text { Difference }(\%) \text { between } \\
\text { southern }\left(10^{\circ} \mathrm{C}\right) \text { and } \\
\text { central }\left(14^{\circ} \mathrm{C}\right) \text { Chile }\end{array}$} & \multicolumn{2}{|c|}{$\begin{array}{c}\text { Difference }(\%) \text { between } \\
\text { central }\left(14^{\circ} \mathrm{C}\right) \text { and } \\
\text { northern }\left(18^{\circ} \mathrm{C}\right) \text { Chile }\end{array}$} \\
\hline & $\begin{array}{l}\text { Early } \\
\text { embryos }\end{array}$ & $\begin{array}{l}\text { Late } \\
\text { embryos }\end{array}$ & $\begin{array}{l}\text { Early } \\
\text { embryos }\end{array}$ & $\begin{array}{l}\text { Late } \\
\text { embryos }\end{array}$ \\
\hline Reproductive output & 0 & - & -28 & - \\
\hline Flapping frequency & 36.4 & 42 & 38.9 & 13 \\
\hline Cost of brooding $\left(\mathrm{min}^{-1}\right)$ & 0 & 125 & 0 & 47 \\
\hline Incubation time & \multicolumn{2}{|c|}{-76} & \multicolumn{2}{|c|}{-60} \\
\hline $\begin{array}{l}\text { Cost of brooding } \\
\text { (per incubation period) }\end{array}$ & - & 29 & - & 15 \\
\hline
\end{tabular}

such as reduced competition, reduced predation rate, avoidance of predators, and improved ability to obtain food (Belk 1977, Reaka 1979, Hines 1982, Jones \& Simons 1983).

Field data showed consistent differences between the northern site and the other 2 locations in most of the variables analyzed. RO increased with latitude from central Chile southward, principally because embryo volume and weight also increased toward the south. Fecundity did not show a clear trend. The same latitudinal trend in RO was reported by Lardies \& Castilla (2001) for Pinnaxodes chilensis between 23 and $39^{\circ} \mathrm{S}$ along the Chilean coast. The link between field data and laboratory conditions can be established by analyzing the patterns of (1) embryo losses, (2) events of oxygen provision, and (3) flapping frequency. Embryo loss (the difference in fecundity between females carrying earlyand late-stage embryos) was found only in the northern site, and no evidence of it occurring was found in the 
other 2 locations. Embryo losses have been reported in several species of Brachyuran crabs (Kuris 1991). Prior evidences for other Brachyuran species (Fernández et al. 2000), and personal observations in Cancer setosus, suggest that embryo losses are a consequence of female ventilation of the embryo mass. There are few examples of latitudinal patterns of embryo losses, and the existing ones do not show a clear pattern (Nephrops norvegicus, Fariña et al. 1999; P. chilensis, Lardies \& Castilla 2001). The potential link between female ventilation and egg losses is suggested by an increase in the frequency of abdominal flapping with increasing temperature. We think that female crabs respond to the increased oxygen demand of the embryos at higher temperatures by increasing abdominal flapping frequency and oxygen provision to the embryos. Similar patterns of female response to embryo oxygen demand have been reported throughout embryo development (Baeza \& Fernández 2002, Fernández et al. 2002). The change in female brooding behavior (abdominal flapping frequency) produces a higher rate of oxygen supply (Fig. 4A,C) and generates a similar pattern of exposure to limiting (low) oxygen levels at different temperatures (Fig. 4B). It is interesting to note that oxygen conditions in the embryo mass (proportion of time that the embryos are exposed to low oxygen levels) do not vary among temperatures. The consideration of the effect of temperature on embryo losses is not trivial, because it is another factor associated to maternal care and the cost of brooding.

Although no differences in oxygen consumption were detected between female crabs carrying earlystage masses and nonbrooding females, the rate of oxygen consumption increased in females carrying late-stage embryos. The pattern that we report can be explained by an increase in the effort to ventilate the embryos, measured as the frequency of abdominal flapping and related to the increasing oxygen demand between early- and late-stage embryos. Previous studies have reported a strong correlation between abdominal flapping and oxygen provision to the embryos (Baeza \& Fernández 2002). The difference in oxygen consumption of brooding females carrying late-stage embryos per unit of time, with respect to other female conditions (carrying early-stage embryos and nonbrooding), varies with temperature. The most dramatic increase in oxygen consumption of brooding females occurs between 10 and $14^{\circ} \mathrm{C}$, with a $125 \%$ increase, while a $47 \%$ increase was detected between 14 and $18^{\circ} \mathrm{C}$. This variation relates to the oxygen demand of the late-stage embryos, which increases by 172 and $35 \%$ between 10 and $14^{\circ} \mathrm{C}$ and between 14 and $18^{\circ} \mathrm{C}$, respectively. It is important to emphasize that, in general, field data showed a larger contrast between 14 and $18^{\circ} \mathrm{C}$ than between 10 and $14^{\circ} \mathrm{C}$, while laboratory data obtained using females from central Chile $\left(14^{\circ} \mathrm{C}\right)$ acclimated to the other 2 experimental temperatures displayed a larger difference between 10 and $14^{\circ} \mathrm{C}$ than between 14 and $18^{\circ} \mathrm{C}$. This may indicate that there was a differential effect on females acclimated at different temperatures; however, the effect of temperature on patterns of oxygen provision, female behavior, and cost of brooding is still clear. In accordance with capacity-limited ventilation and circulation observed at the upper end of the thermal tolerance window (Frederich \& Pörtner 2000), the frequency of abdominal flapping may approach capacity limitation in females from the central locality acclimated to $18^{\circ} \mathrm{C}$, evidenced by the lower increment between 14 and $18^{\circ} \mathrm{C}$ than between 10 and $14^{\circ} \mathrm{C}$. For individuals from the northern site, this limitation is probably shifted to higher temperatures. Mechanisms visible from our data, which should help to overcome oxygen limitations at warm temperatures in the northern locality, and reduce the cost of brooding at high temperatures, include a reduction in embryo volume. Further effort is needed to identify the metabolic mechanisms involved in defining the thermal tolerance limits of Cancer setosus populations (adults and embryos), e.g. by establishing their level of oxygen demand (cf. Pörtner 2002) as well as the trade-off between embryonic oxygen demand and the cost of brooding at various temperatures.

The increase in the cost of brooding per unit of time with increasing temperature has a direct effect on the total cost of brooding, in spite of the differences in incubation time. We made a rough calculation of brooding cost related to oxygen provision (not taking into account embryo losses) using the average increase in incubation time with decreasing temperature for Brachyuran crabs (Wear 1974), and found that the cost of oxygen provision during the whole incubation period increases with increasing temperature. We estimated a $29 \%$ increase in brooding cost between 10 and $14^{\circ} \mathrm{C}$, and a $15 \%$ increase between 14 and $18^{\circ} \mathrm{C}$. Although it is too early to increasing patterns of $\mathrm{RE}$ per reproductive event for Cancer setosus, since only some of the costs associated to reproduction have been estimated, it is clear that investment in eggs may follow the opposite pattern to investment in oxygen provision. We think that there is a trade-off between investment in eggs and the cost of providing oxygen to the embryos at different temperatures (latitudes). However, the trade-off between investment in eggs and the cost of providing oxygen to the embryos may differ among crab species exhibiting different body sizes or egg sizes. Results also suggest that weight of the embryo mass alone is a poor indicator of total investment in reproduction among Brachyuran crabs, since it depends on the environmental conditions and 
the investment in other reproductive aspects. This pattern may not be exclusive to Brachyuran crabs, but may also apply to other marine invertebrates since oxygen limitation during early development occurs in other brooding species (Booth 1995, Strathmann \& Strathmann 1995, Cohen \& Strathmann 1996, Lee \& Strathmann 1998).

Acknowledgements. We are grateful to Iván Albornoz, Antonio Baeza, Sandra Cifuentes, Alejandro Muñoz, Fernando Ogalde and Nathaly Ruiz-Tagle for their help. We thank 4 anonymous reviewers for their helpful comments. This study was supported by the FONDAP \#3 (Crustaceans), the Volkswagen Foundation, the Humboldt Foundation, and FONDAPFONDECYT (Grant 1501-0001). We also thank the Deutscher Akademischer Austauschdienst (DAAD). This paper was completed during the tenure of the Fondecyt grant 1020860.

\section{LITERATURE CITED}

Baeza JA, Fernández M (2002) Active brood care in Cancer setosus (Crustacea: Decapoda): the relationship between female behaviour, embryo oxygen consumption, and the cost of brooding. Funct Ecol 16:241-251

Belk D (1977) Evolution of egg size strategies in fairy shrimps. Southwest Nat 22:99-105

Booth D (1995) Oxygen availability and embryonic development in sand snail egg masses. J Exp Biol 198:241-247

Brown RA, Russell-Hunter WD (1978) Reproductive effort in molluscs. Oecologia 37:23-27

Chapelle G, Peck LS (1999) Polar gigantism dictated by oxygen availability? Nature 399:114-115

Clarke A (1987) Temperature, latitude and reproductive effort. Mar Ecol Prog Ser 38:89-99

Cohen C, Strathmann R (1996) Embryos at the edge of tolerance: effects of environment and structure of egg masses on supply of oxygen to embryos. Biol Bull 190:8-15

Coma R, Zabala M, Gili J (1995) Sexual reproductive effort in the mediterranean gorgonian Paramuricea clavata. Mar Ecol Prog Ser 117:185-192

Diesel R, Schuh M (1998) Effects of salinity and starvation on larval development of the crabs Armases ricordi and A. roberti (Decapoda: Grapsidae) from Jamaica, with notes on the biology and ecology of adults. J Crustacean Biol 18: 423-436

Fariña AC, Freire J, González-Gurriarán E (1999) Fecundity of the Norway lobster Nephrops norvegicus in Galicia (NW Spain) and a review of geographical patterns. Ophelia 50(3):177-189

Fernández M, Bock C, Pörtner HO (2000) The cost of being a caring mother: the ignored factor in the reproduction of marine invertebrates. Ecol Lett 3:487-494

Fernández M, Pardo LM, Baeza JA (2002) Patterns of oxygen supply in embryo masses of Brachyuran crabs throughout development: the effect of oxygen availability and chemical clues in determining female behavior. Mar Ecol Prog Ser 245:181-190

Fernández M, Ruiz-Tagle N, Cifuentes S, Pörtner HO, Arntz W (2003) Oxygen dependent asynchrony of embryonic development in egg masses of Brachyuran crabs. Mar Biol (in press)

Frederich M, Pörtner HO (2000) Oxygen limitation of thermal tolerance defined by cardiac and ventilatory perfor- mance in spider crab, Maja squinado. Am J Physiol 279: R1531-R1538

Grant A (1990) Mode of development and reproductive effort in marine invertebrates: should there be any relationship? Funct Ecol 4:128-130

Hartnoll RG, Paul K (1982) The embryonic development of attached and isolated eggs of Carcinus maena. Int J Invertebr Rep 5:247-252

Havenhand JN, Todd CD (1989) Reproductive effort of the nudibranch molluscs Adalaria proxima and Onchidoris muricata: an evaluation of techniques. Funct Ecol 3: 153-163

Hines AH (1982) Allometric constraints and variables of reproductive effort in Brachyuran crabs. Mar Biol 69: $309-320$

Hines AH (1986) Larval patterns in the life histories of Brachyuran crabs (Crustacea, Decapoda, Brachyura). Bull Mar Sci 39:444-466

Hoagland K (1979) The behavior of three sympatric species of Crepidula form the Atlantic, with implications for evolutionary ecology. Nautilus 93:143-149

Hughes RN, Roberts DJ (1980) Reproductive effort of Winkles (Littorina spp.) with contrasted methods of reproduction. Oecologia 47:130-136

Jones MB, Simons MJ (1983) Latitudinal variation in reproductive characteristics of a mud crab, Helice crassa. Bull Mar Sci 33(3):656-670

Kenagy J, Masman D, Sharbaugh S, Nagy K (1990) Energy expenditure during lactation to litter size in free-living golden-mantled ground squirrels. J Anim Ecol 59:73-88

Kuris AM (1991) A review of patterns and causes of crustacean brood mortality. In: Schram FR (ed) Crustacean issues, Vol. 7. Balkema, Rotterdam, p 117-141

Lardies M, Castilla JC (2001) Latitudinal variation in the reproductive biology of the commensal crab Pinnaxodes chilensis (Decapoda: Pinnotheridae) along the Chilean coast. Mar Biol 139:1125-1133

Lee CE, Strathmann RR (1998) Scaling of gelatinous clutches: effects of siblings' competition for oxygen on clutch size and parental investment per offspring. Am Nat 151: 293-310

Masman D, Dijkstra C, Daan S, Bult A (1989) Energetic limitation of avian parental effort: filed experiments in the kestrel (Falco tinninculus). J Evol Biol 2:435-456

Menge B (1974) Effect of wave action and competition on brooding and reproductive effort in the seastar, Leptasterias hexactis. Ecology 55:84-93

Monaghan P, Nager R (1997) Why don't birds lay more eggs? Trends Ecol Evol 12(7):270-274

Naylor JK, Taylor EW, Bennett DB (1999) Oxygen uptake of developing eggs of Cancer Pagurus (Crustacea: Decapoda: Cancridae) and consequent behaviour of ovigerous females. J Mar Biol Assoc UK 79:305-315

Pandian TJ (1994) Arthropods-Crustacea. In: Adiyodi KG, Adiyodi RG (eds) Reproductive biology of invertebrates. Oxford and IBH Publishing, Kerala, p 1-165

Perron FE (1982) Inter and intraspecific patterns of reproductive effort in four species of cone shells (Conus spp.). Mar Biol 68:161-167

Pörtner HO (2002) Environmental and functional limits to muscular exercise and body size in marine invertebrate athletes. Comp Biochem Physiol A 133:303-321

Reaka ML (1979) The evolutionary ecology of life history patterns in stomatopod Crustacea. In: Stancyk WE (ed) Reproductive ecology of marine invertebrates. University of South Carolina Press, Columbia, p 235-260 
Ruiz-Tagle N, Pörtner HO, Fernández M (2002) Full-time mothers: daily rhythms in brooding and non-brooding behaviors in Brachyuran crabs. J Exp Mar Biol Ecol 276: 31-47

Schuh M, Diesel R (1995) Effects of salinity, temperature, and starvation on the larval development of Armases (= Sesarma) miersii (Rathbun, 1897), a semiterrestrial crab with abbreviated development (Decapoda: Grapsidae). J Crustac Biol 15(2):205-213

Servicio Hidrogáfico y Oceanógrafico de la Armada de Chile (1996) Atlas Oceanográfico de Chile. Vol. 1. Valparaíso

Stearns S (1992) The evolution of life histories. Oxford University Press, New York

Steele DH, Steele VJ (1975) Egg size and duration of embryonic development in Crustacea. Int Rev Hydrobiol 60(5): 711-715

Strathmann R, Strathmann M (1995) Oxygen supply and limits on aggregation of embryos. J Mar Biol Assoc UK 75:413-428

Editorial responsibility: Otto Kinne (Editor),

Oldendorf/Luhe, Germany
Todd C (1990) Mode of development and reproductive effort in marine invertebrates: is there any realitonship? Funct Ecol 4(1):132-133

Vargas LM (1995) Descripción del desarrollo embrionario de Cancer polyodon Poepping 1836 (Crustacea: Decapoda: Brachyura) y efectos de la temperatura, bajo condiciones de laboratorio. BSc thesis, Universidad Católica del Norte, Coquimbo

Wear RG (1974) Incubation in British decapod Crustacea, and the effects of temperature on the rate and success of embryonic development. J Mar Biol Assoc UK 54:745-762

Wheatly MG (1981) The provision of oxygen to developing eggs by female shore crabs (Carcinus maenas). J Mar Biol Assoc UK 61:117-128

Willows R (1990) Mode of development and reproductive effort in marine invertebrates: no relationship predicted by life-history theory? Funct Ecol 4(1):130-132

Zar JH (1996) Biostatistical analysis. Prentice Hall, Englewood Cliffs, NJ

Submitted: August 7, 2002; Accepted: December 3, 2002 Proofs received from author(s): March 14, 2003 